\title{
LER É CIVILIZADO, ESCREVER É BÁRBARO: CONSTRUÇÕES TEXTUAIS COM ADOLESCENTES APRENDENTES EM TEMPOS PANDÊMICOS
}

\author{
READ IS CIVILIZED, WRITE IS BARBARIC: TEXTUAL CONSTRUCTIONS WITH TEENAGE \\ APPRENTICES IN PANDEMIC TIMES \\ LEER ES CIVILIZADO, ESCRIBIR ES BÁRBARO: CONSTRUCIONES TEXTUALES CON \\ ADOLESCENTES APRENDENTES EN TIEMPOS PANDEMICOS
}

\author{
Edson Gomes Evangelista \\ (iD) 9 \\ Doutor em Educação \\ Professor de Língua Portuguesa, \\ Língua Espanhola e Respectivas \\ Literaturas no IFMT, Campus Bela \\ Vista \\ Programa de Pós-Graduação em \\ Ensino (PPGEN/IFMT) \\ edson.evangelista@blv.ifmt.edu.br
}

\begin{abstract}
Resumo
De repente, não mais que de repente, fez-se necessário o ensino emergencial virtual, de noite para um dia, não mais presença pessoalizada nas interações face a face, corporificadas em sala de aula. Ante a conjuntura ensejada pelo pandêmico, como mobilizar discentes adolescentes para produzirem textos, excogitarem e se apropriarem do próprio processo de escrita? Da necessária e urgente resposta a esta indagação erigiu-se a experiência narrada aqui. Buscou-se, por meio de uma sequência didática, co-construir com estudantes do Ensino Médio integrado a Cursos Técnicos, artigos de opinião de modo que com a edição, reescrita, apropriação metalinguística e publicitação, ensejaram a produção de vídeos compartilhados em diferentes redes sociais. A produção enunciada foi factível porque as relações docente/discentes se ampliaram e adquiriram o propósito político, converteu-se em ato político com vistas a alcançar outros adolescentes aprendentes em contextos de escolas públicas.
\end{abstract}

Palavras-chave: Ensino Emergencial. Produção de Textos. Sequência Didática.

Recebido em: 5 de agosto de 2021.

Aprovado em: 9 de novembro de 2021.

Como citar esse artigo (ABNT):

EVANGELISTA, Edson Gomes. Ler é civilizado, escrever é bárbaro: construções textuais com adolescentes aprendentes em tempos pandêmicos. Revista Prática Docente, v. 6, n. 3, e094, 2021. http://doi.org/10.23926/RPD.2021.v6.n3.e094.id1291 


\begin{abstract}
Suddenly, no more than suddenly, it was necessary virtual emergency teaching, overnight, no longer personalized presence in face-to-face interactions, embodied in the classroom. Before the situation caused by the pandemic, how to mobilize adolescent students to produce texts, figure and appropriate the writing process itself? The experience narrated here was erected from the necessary and urgent response to this inquiry. Through a didactic sequence, we sought to co-build with high school students integrated with Technical Courses, opinion articles so that with editing, rewriting, metalinguistic appropriation and advertising, they led to the production of videos shared in different social networks. The enunciated production was feasible because the relations of teachers/students expanded and acquired the political purpose, has become a political act with a view to reaching other adolescent learners in public school contexts.
\end{abstract}

Keywords: Emergency Education. Production of Texts. Didactic sequence.

\title{
Resumen
}

De pronto, súbitamente, se ha hecho necesario el aprendizaje virtual, en el transcurso de una noche para el día, no se pudo más presencia personal, interactuaciones cara a cara, vigentes en aula de clases. Ante la coyuntura enmarcado por el tiempo pandémico, ¿cómo movilizar a los estudiantes para producir textos, reflexionar y si apropiaren del propio proceso de escritura? De la búsqueda urgente de respuesta para esta pregunta surgió la experiencia narrada aquí. Tuvo como reto, a través de una secuencia didáctica, construir colaborativamente con estudiantes de la enseñanza media integrada a Cursos Técnicos, artículos, así mismo, llevarlos a comprender a través de la reescrita y publicitación las estructuras del género textual mencionado y gravar vídeos sobre el proceso de escrita de estos textos con objetivo de compartirlos en las redes sociales. La construcción fue posible a la causa del acercamiento virtual en las interactuaciones del profesor con los estudiantes y de estos unos con los otros, por fin, al trabajo de producción escrita se añade un propósito político, desde el abordaje metodológico se ha convertido en ato político hacia otros adolescentes, estudiantes en contextos de escuelas públicas.

Palabras clave: Aprendizaje virtual. Producción de Textos. Secuencia Didáctica. 


\section{INTRODUÇÃ̃o}

Neste texto, por meio da narrativização (CLANDININ, D. J.; CONNELLY, F. M.; 2011) de experiências construídas com estudantes do Ensino Médio Integrado a Cursos Técnicos, convida-se à reflexão sobre o aprender e o ensinar em tempos de exceção, tempos de luto e ressignificação, tempos pandêmicos. A narrativa foi erigida com fulcro no acontecer da sala de aula virtual. Espaço de dinamicidade paradoxal, porque professor e estudantes, reunidos na virtualidade, estabelecem outros modos de interação, estão próximos e distantes concomitantemente, porquanto à metáfora com que se inicia este artigo, não se escolheu aleatoriamente.

Neste sentido, cumpre ressaltar que se buscou, por meio de uma sequência didática, coconstruir com estudantes do Ensino Médio integrado a Cursos Técnicos, artigos de opinião de modo que, com a edição, reescrita, apropriação metalinguística e publicitação, ensejassem a produção de vídeos compartilhados em diferentes redes sociais. Feitas estas breves considerações preambulares, sintam-se convidados a adentrar os umbrais da escrita que se lhes enuncia.

Bólidos multicoloridos vão se apagando, aos poucos, agora, resta apenas um, dos mais de quarenta havidos antes. Subtitulado: EB. "Professor, esperei o final da aula para dizer que estou lendo aquele livro que o senhor falou, A Peste. Este livro é muito atual, professor! Fiquei pistola". Do outro lado da tela, o docente a incentiva a seguir lendo, ampliando os próprios umbrais no mundo, metaforizou. A enunciação aqui transcrita, ocorreu em meados do mês de julho de 2021. A esta altura, a pandemia originada pelo Sars Covid-19, perdura por um tempo, impossível de mensurar cronologicamente apenas, não obstante, o fato de haver decorrido pouco mais de um ano desde o advento destes trágicos tempos.

A pandêmica peste que tornou atual a leitura do clássico de Albert Camus, transposto mais de meio século desde a primeira publicação, iniciou-se, possivelmente na China, veio chegando cada vez mais perto, perto, pertinho... em 17 de março de 2020 chegou a Mato Grosso e promoveu uma transformação colossal na vida, na morte e no processo de ensinar e aprender no âmbito formal de ensino. De repente, não mais que de repente (DE MORAES, 2020), fez-se necessário o ensino emergencial virtual, de noite para um dia, não mais presença pessoalizada nas interações face a face, corporificadas em sala de aula. Do ensino virtual emergencial, marcado por hercúleos desafios também emergentes em tempos de isolamento social, medo, luto... descobertas, passou-se ao ensino remoto, sem que houvesse tempo - kairós - para traçar 
possíveis rotas, ao caminhar foi-se tracejando o caminho, rearrumando os rumos. Como tão assertivamente relatara Moreira (2020):

O processo de globalização da economia e da comunicação, a evolução das tecnologias e de uma consciência de mundialização em rede têm provocado mudanças acentuadas na sociedade, impulsionando o nascimento de novos paradigmas, modelos, processos de comunicação educacional e novos cenários de ensino e de aprendizagem digital (GARRISON; ANDERSON, 2005). Mas ninguém, nem mesmo os professores que já adotavam ambientes online nas suas práticas, imaginava que seria necessária uma mudança tão rápida e emergencial, de forma quase obrigatória, devido à expansão do COVID 19. (MOREIRA, et al., 2020, p. 352).

No que tange ao ensino emergencial/remoto no Brasil Ferreira Ribeiro (2020) se fez enunciar de modo a ressaltar o recomeço necessário em um contexto que emergiu de repente, não mais que de repente, docentes e discentes experienciando o novo, subitamente

\begin{abstract}
Na pandemia, professores/as de toda geração e estudantes de todos os níveis foram parar na mesma estaca zero. Pode ser que alguns e algumas se aventurem mais, sintam maior familiaridade com certos ambientes digitais, mas, no geral, a crise é ampla. A insegurança e a sensação de recomeço estão em todos/as, que se viram na situação de atuar por meio de plataformas que propiciam uma experiência completamente outra (...) (RIBEIRO, 2020, p.452).
\end{abstract}

Instado a agir na urgência o professor, cujo ensaio narrativiza uma sequência didática, concebida por ele em meio a crise ampla decorrente do contexto pandêmico, tal como apresentado pela autora supracitada entre desconhecimentos e descobertas levadas a cabo em meio ao coletivo de aprendizagem que compõem o grupo de professores, discentes e técnicos do Campus Bela Vista, IFMT. Cônscios de que

\begin{abstract}
A pandemia é uma imensa tristeza, trouxe morte, desemprego, crise. Mas há, enquanto ela ocorre, uma camada dos acontecimentos por conta das pessoas encarregadas de encontrar soluções, detectar problemas antes pouco visíveis, redimensionar outros, arranjar possibilidades, dentro da precariedade. Há, inclusive, quem esteja ocupado/a em pensar uma educação melhor (e não necessariamente guiada pelo lucro) e mesmo uma convivência mais razoável entre todos/as. (RIBEIRO, 2020, p.452)
\end{abstract}

$\mathrm{Na}$ conjuntura posposta é que se concebeu e foram desenvolvidas as ações didático pedagógicas das quais resultam este ensaio, cujo objetivo é narrativizar experiências elaboradas no primeiro semestre de 2021, com acadêmicos do Ensino Médio Integrado ao ensino técnico em Química e ao ensino técnico em Meio Ambiente, na disciplina Produção de Textos II; Instituto Federal de Mato Grosso, Campus Bela Vista.

Delineada com fulcro na Pesquisa Narrativa (CLANDININ.; CONNELLY; 2011), a produção dos dados interpretados ocorreu, conforme enunciado ao longo de dois períodos letivos, coincidentes com a implantação do Ensino Remoto Emergencial. Mencionada metodologia permite compreender as histórias contadas e vividas tanto como fenômeno eminentemente humano e humanizador quanto como Método de Investigação. Posto que, 
[...] dizer que se entendemos o mundo de forma narrativa, como fazemos, então faz sentido estudá-lo de forma narrativa. Para nós, a vida- como ela é para nós e para os outros - é preenchida de fragmentos narrativos, decretados em momentos históricos de tempo e espaço, e refletidos e entendidos em termos de unidades narrativas e descontinuidades. (CLANDININ; CONNELLY, 2011, p. 48).

A escolha da Pesquisa Narrativa, por conseguinte, pareceu a mais oportuna, pois vivenciou-se no período mencionado a descontinuidade de modos de fazer e de ser, porquanto a emergência de momentos históricos outros impactaram decisivamente a vida e suscitaram novas perspectivas educacionais, cuja compreensão está ainda por ser feita, não obstante, é fato que ao mundo, mais do que antes, faz-se necessário entender de forma narrativa. Neste mesmo diapasão, argumenta-se em favor de dotar de sentidos as novas experiências erigidas nestes tempos pressurosos e lânguidos, mormente aquelas experiências elaboradas por estudantes e professores.

Em sendo assim, uma vez mais a Pesquisa Narrativa emerge como potencializadora do entendimento requerido nesta conjuntura, pois almeja, por meio do ouvir, contar e viver histórias o revisitar de experiências com o fito de suscitar os sentidos a elas atribuídos por quem as viveu, configuraria assim, o experienciar de experiências, conceito cunhado a partir do entrelaçamento entre tempo, lugar e pessoas em interação, conforme assentido pelo docente que assina este artigo, em tese de doutoramento apresentada ao Programa de Pós Graduação em Educação da Universidade Federal de Mato Grosso, no ano de dois mil e dezessete. Uma vez que, como insistem Clandinin e Connely (2011, p. 65-66):

No pensamento narrativo o contexto está sempre presente. Isso inclui noções tais como contexto temporal, espacial e contexto de outras pessoas. O contexto é necessário para dar sentido a qualquer pessoa, evento ou coisa [...]. No pensamento narrativo, a pessoa em contexto é o que interessa.

\section{FUndaMentaÇÃo TeÓRICA}

Sustentam a prática que suscitou a experiência aqui narrativizada, em termos epistemológicos os trabalhos de Mikhail Bakhtin, mormente os conceitos constantes em Estética da Criação Verbal, referentes à Enunciação Discursiva. Em conformidade com o Cientista Russo:

O fato de ser ouvido, por si só, estabelece uma relação dialógica. A palavra quer ser ouvida, compreendida, respondida e quer, por sua vez, responder à resposta, e assim ad infinitum. Ela entra num diálogo em que o sentido não tem fim (entretanto ele pode ser fisicamente interrompido por qualquer um dos participantes). (BAKTHIN, 2003, p. 199). 
Dar audiência ao ser com o qual se interage, escutá-lo desde o lado de dentro de seu próprio enunciar configura-se como importante princípio no processo educacional em âmbito escolar formal, incluídos os meandros da Língua Portuguesa. O dialogismo tal como postulado pelo autor supracitado potencializa sobremaneira a proficuidade do ato de aprender, não obstante, na infinidade de registros que pairam entre a Língua Portuguesa - Norma Padrão - e as línguas portuguesas - variantes, por meio das quais, milhões de brasileiros sonham, falam, comem, vivem e morrem nestes diversos brasis, há um limite muito tênue entre o convidar o estudante a se enunciar ou ensiná-lo a se calar ou na melhor das conjecturas, enclausurar no âmago da própria variante linguística, no mesmo diapasão que se fez enunciar Oswald de Andrade

\author{
Pronominais \\ Dê-me um cigarro \\ Diz a gramática \\ Do professor e do aluno \\ E do mulato sabido \\ Mas o bom negro e o bom branco \\ Da Nação Brasileira \\ Dizem todos os dias \\ Deixa disso camarada
}

Me dá um cigarro (ANDRADE, Oswald de, 2002).

Destarte, o ensino/aprendizagem de Língua Portuguesa pode se dar sob múltiplos enfoques e abordagens metodológicas. Enfoques e abordagens que sustentam toda uma diversidade de práticas pedagógicas e se entrelaçam ao longo do percurso de formação de docentes que atuam com a mencionada disciplina. Desde esta perspectiva, as produções das quais resultam este texto fizeram-se exequíveis em virtude da compreensão da Língua como enunciação discursiva (BAKTHIN, 2003); outrossim, possibilitou o engendrar das produções mencionadas, a teoria dos gêneros discursivos tal como enunciada por Mikhail

Todas as esferas da atividade humana, por mais variadas que sejam, estão sempre relacionadas com a utilização da língua. Não é de surpreender que o caráter e os modos dessa utilização sejam tão variados como as próprias esferas da atividade humana, o que não contradiz a unidade nacional de uma língua. A utilização da língua efetua-se em forma de enunciados (orais e escritos), concretos e únicos, que emanam dos integrantes duma ou doutra esfera da atividade humana. $\mathrm{O}$ enunciado reflete as condições específicas e as finalidades de cada uma dessas esferas, não só por seu conteúdo (temático) e por seu estilo verbal, ou seja, pela seleção operada nos recursos da língua - recursos lexicais, fraseológicos e gramaticais —, mas também, e sobretudo, por sua construção composicional. Estes três elementos (conteúdo temático, estilo e construção composicional) fundem-se indissoluvelmente no todo do 
enunciado, e todos eles são marcados pela especificidade de uma esfera de comunicação. Qualquer enunciado considerado isoladamente é, claro, individual, mas cada esfera de utilização da língua elabora seus tipos relativamente estáveis de enunciados, sendo isso que denominamos gêneros do discurso. (BAKTHIN, 2003, p. 261).

A ancoragem advinda da conceitualização de gênero do discurso, assim como consta no entrecho precedente aliada ao conceito de enunciação discursiva constituíram sustentáculos, cuja apropriação veio se dando ao largo de mais de duas décadas de atuação docente do autor deste ensaio. No decorrer desta trajetória de formação, às produções desenvolvidas pelos acadêmicos se lhes foi atribuindo novos sentidos, de modo que, passou-se a concebê-las como discursos, cuja função não se esgota na edição realizada individualmente ou em grupo; a esta etapa de aprendimentos, necessário se faz inseri-las na dialogia interdiscursiva, por meio da publicização destas produções, a fim de que possam integrar as respectivas esferas discursivas, tornando-se responsivas ad infinitum.

Ressalte-se, outrossim, que a relevância e pertinência dos postulados Bakhtinianos no que concerne à Teoria dos Gêneros Discursivos reside, dentre outros, no fato de que no bojo mesmo de mencionada Teoria está contemplado o devir histórico da evolução dos Gêneros discursivos. Assim, pois, tornou-se factível fundamentar o labor educacional em tempos de Ensino Remoto Emergencial em estudos do Linguística Russo. Haja vista, a compreensão de que uma vez estando relacionados a esferas das atividades humanas os gêneros evoluem, de modo que ante a necessidade de se erigir novos modos de interação pedagógica em virtude da virtualidade das salas de aula durante a pandemia, ao docente pesquisador apresentou-se como possibilidade a reelaboração desta mirada teórica; concebida por este último tendo em vista sempre o ensino presencial, expandindo-a para açambarcar a nova configuração que se lhe apresentará contextualmente.

Entretanto, Bakhtin foi sobretudo um linguista, cientista dedicado a compreender a linguagem antes que didatizá-la. Professor e pesquisador da língua em que sonha, projeta e perscruta o porvir, este ensaísta, deparou-se com a necessidade de burilar para além da Teoria Bakhtiniana possibilidades de traduzir uma teoria epistemológica da Linguagem em Teoria Pedagógica para o ensino de línguas. Tarefa dangerosíssima, fazenda de toda uma vida. Fato é que no tempo presente, tem sido encontrado sustentáculo na aproximação entre a Teoria dos Gêneros Discursivos e a Teoria dos Gêneros Textuais. Aproximação cuidadosa, quase uma recriação, emergida da trajetória de formação que vem sendo delineada pelo docente que narra esta experiência, construção eclética pautada em conceitos temporal, conceitualmente e 
contextualmente diversos. Cômpito no qual se encontram as investigações de um pensador russo de meados do século passado, professores europeus que publicizam os respectivos estudos em fins daquele mesmo século e o docente que busca dar sentido à própria prática no tempo presente.

Desta mirada teórica e epistemo-pedagógica, ainda em construção resultou a produção realizada por acadêmicos do Ensino Médio integrado a Cursos Técnicos na Disciplina de Produção de textos, processo que será narrativizado na próxima seção deste ensaio. Antes, contudo, cumpre esclarecer que a aproximação entre os postulados Baktinianos e os estudos delineados por Dolz e Schneuwly (2004), configura-se muito mais como um lugar de recriação teórica da prática no ensino/ aprendizagem na Área de Linguagens. Lugar de investigações, tentativas e erros, mas também de perscrutar recomeços e novas possibilidades, nestes tempos pandêmicos; conforme poderá o leitor depreender no relato que se segue.

\section{ENUnCIAÇÃo: diAlogia RESPONSIVA NO PROCESSO DE PRODUZIR TEXTOS EM CURSOS TÉCNICOS INTEGRADOS AO ENSINO MÉDIO}

O encontro síncrono, com estudantes do quarto semestre de Ensino Médio Integrado a Cursos Técnicos, IFMT, Campus Bela Vista, iniciou-se decorridos cinco minutos do horário aprazado, 9h35. Nos dez minutos precedentes o docente encetara uma conversação com as primeiras docentes a adentrarem na sala de aula virtual. Saudações entretecidas desde uma perspectiva mais pessoal, percepções sobre o estado de saúde de parentes e familiares com os quais convivem mais proximamente; perquirições sobre o desenvolvimento das produções acordadas em uma sequência de produções interrelacionadas, cujo início data de vinte dias anteriores.

A sequência supracitada foi erigida com fulcro nos trabalhos desenvolvidos por Dolz e Schneuwly (2004), todavia encontra sustentação teórica nos conceitos de enunciação e gêneros discursivos (BAKTHIN, 2003). Acorde às demandas do tempo presente, foi concebida para ser implementada no ambiente virtual, plataforma Google Classroom, com mediações também pelo Gmail, bem como pelo aplicativo WhatsApp. Nesta sequência didática as produções, tanto em grupo quanto individuais, foram precedidas pela disponibilização do material de estudos a posteriori, coincidindo, neste com a Metodologia de Sala Invertida com projeto colaborativo de aprendizagem, tal como conceituada por BERGMANN (2018), a cada encontro síncrono os docentes eram instados a se enunciarem, mediados por perguntas suleadoras de novas percepções e/ou elaborações concernentes a processo de produção, edição e publicização de 
textos, gênero: artigo de opinião; dialogia mediada sempre pelo docente. No intercurso de vinte aulas, houve dez encontros síncronos, o equivalente a outras dez, deu-se sob a forma de produções assíncronas. A conceituação de sequência didática tal como preconizada por Dolz e Schneuwly (2004), constitui ponto de partida para o trabalho ora apresentado. De conformidade com estes pesquisadores suíços, sequência didática é "um conjunto de atividades escolares organizadas, de maneira sistemática, em torno de um gênero textual" (DOLZ, NOVERRAZ; SCHNEUWLY; 2004, p. 97).

Desde esta perspectiva o conceito de gênero textual se configura como megainstrumento, cuja abordagem sistemática por meio de dada sequência didática deve possibilitar aos aprendentes a reconstrução histórico social do gênero. Outrossim, a compreensão deve transcender a escrita instrumental apenas e, ensejar possibilidades metalinguísticas, ou seja, mais que enunciar se faz necessário compreender todos os aspectos que presidem e sustentam a escolha por se enunciar por meio deste ou daquele gênero textual. Estes constituem princípios basilares da sequência didática neste texto narrativizada.

O preâmbulo da sequência didática a que se tem feito referência se deu a partir da explicitação sintética do lugar teórico do qual o professor se enuncia, dito de outro de modo, foi explicitado que a Redação do Exame Nacional do Ensino Médio desde este lugar de enunciação define-se com o artigo de opinião. Feitas estas explicitações, os acadêmicos foram perquiridos sobre os aspectos fulcrais do gênero textual artigo de opinião. Em conversação dialogada realizou-se a revisão dos conceitos de: Tema, Tese, Argumentos, ademais, de se tangenciar diferentes modos de se introduzir um artigo de opinião. Foram incumbidos de investigar e identificar os elementos estruturantes de um artigo de opinião escolhido dentre as edições do Exame Nacional do Ensino Médio fizeram-no como produção assíncrona.

No encontro síncrono seguinte, deu-se a publicização de tais produções junto aos companheiros de classe, feitas as ponderações pertinentes, se lhes foi atribuída a tarefa de produzir um artigo de opinião com temática atinente a interações humano/ambiente - visto serem acadêmicos de cursos técnicos integrados a Meio Ambiente e Química. A produção individual foi postada na plataforma Google Classroom. Após a leitura e, tecidas considerações referentes a Coerência, Coesão e Progressão Textual, fez-se edição coletiva de textos e reescrita, sucedida pela publicização daqueles, cujos autores se sentiram confiantes para fazê-lo junto aos colegas de sala de aula virtual, ações que decorreram ao largo de três encontros síncronos, 
intercalados com produções assíncronas, mediadas sempre por considerações do docente, via comentários na plataforma ou no aplicativo supracitados.

Sequencialmente, foram conclamados a produzirem artigos de opinião em duplas ou trios, surpreenderam-se com a proposição, entretanto levaram a cabo a produção. Envolvidos nesta trama profícua de produções muitos acadêmicos passaram a solicitar que aqueles textos que produziam fossem editados nos encontros síncronos. Neste ínterim, lhes foi apresentado o conceito de metalinguagem, corolário da perspectiva de se constituir como um escritor cônscio das dimensões daquilo que enuncia (BAKTHIN, 2003). Neste diapasão, intercalou-se produções individuais e em grupo, sempre do gênero artigo de opinião. Assim, foi lhes atribuída a tarefa de lerem pautado nesta percepção metalinguística a redação de um discente que havia logrado novecentos e oitenta pontos na edição no Exame Nacional do Ensino Médio e identificarem as razões linguísticas que a impediram de alcançar a nota máxima no certame, realizado no ano de dois mil e vinte.

Elaboradas as construções narradas, encaminhou-se para a análise das próprias produções - metacognição - para tanto produziram em grupo novos artigos de opinião, os editaram, reescreveram-nos e segundo parâmetros de produção requeridas aos artigos apresentados à Banca Corretora do Exame Nacional do Ensino Médio, atribuíram a si mesmos a pontuação, todo esse processo, editou-se para produzir os vídeos apresentados ao professor de Produção de Textos II. Vídeos, cuja relevância levou a proposição que fossem publicitados em redes sociais com o fito de alcançar àqueles estudantes, os quais neste contexto pandêmico, foram obstados de elaborar as construções concernentes ao gênero textual tão impactante, haja vista constituir-se em uma das provas requeridas para o ingresso em Universidades Públicas de todo o País.

Entretecidos os acordos, traçada a estratégia para que os vídeos fossem publicitados, encerrou-se aquele encontro síncrono. De par em par as bolinhas multicoloridas foram se extinguindo, até restarem somente duas, um bólido alaranjado, incandescência, que subsistiu ao outro, enunciou-se: "Professor, esperei o final da aula para dizer que estou lendo aquele livro que o senhor falou, A Peste. Este livro é muito atual, professor! Fiquei pistola”.

\section{Resultados E Discussão}

Há tempos, na trama multifacetada que ultrapassa o ardor e a dor, o docente, cuja experiência foi narrativizada, ouviu de um amigo: "Ler é civilizado, escrever é bárbaro" - ao falar do escrever assumiu a postura de encurvar-se sobre a mesa. Transcorrido o tempestuoso 
intercurso de compor uma Tese (ressalte-se que a inicial maiúscula é proposital, visa a aproximar os caminhos percorridos tanto por doutorandos, quanto por estudantes do ensino médio, com o fito de destacar que, resguardadas as especificidades, escrever é sempre laborioso) as lições decorrentes daquela conversação seguem ecoando na ação do professor ensaísta. Retumbaram fortemente em tempos de Ensino Emergencial, sucedido por Ensino Remoto, ambos solaparam a presença partilhada no mesmo espaço entre docentes e discentes, ergueram muros, transpostos a duras penas, precariamente, pela virtualidade. Escrever é bárbaro, porquanto requer a construção de autêntica dialogia, caminhada na qual se partilha o passo, o saber, o ignorar rumo à travessia do mais ser.

Durante o confinamento, a presença acontece via computador, pela participação de estudantes em aulas virtuais, por meio de plataformas que são metáforas de prédios escolares, com professores às vezes desfocados, às vezes só voz por trás de uns slides compartilhados; a presença é computada automaticamente, por logins registrados no sistema ou por pontinhos verdes num menu, à esquerda. O silêncio não é mais um bom sinal. A falta da manifestação por escrito é sentida, muito sentida. Enquanto um/a professor/a explica, os/as estudantes trocam ideias no chat ou em todos os recursos fora de que eles tiverem: WhatsApp, Discord, etc. É a conversa paralela que não será sequer percebida pelo/a docente em exposição. (RIBEIRO, 2020, p.453).

Tempos pandêmicos, virtualidade erigida, novas emergências, urgências, novos modos de fazer, aprender, seguir dotando de sentidos a vida. Eis o contexto que ensejou o experienciar da experiência contada. Nestes tempos áridos o ato de partilhar e acompanhar a Produção Escrita, ação bárbara, tornou-se desafio sobre humano, não obstante, somente pode se dar entre humanos no necessário processo de continuar expandindo o processo de humanização.

A produção enunciada foi factível porque as relações docente/discentes se ampliaram e adquiriram o propósito político, por assim dizer, na medida que entrelaçaram na virtualidade, tempos, histórias e significados capazes de inserir o texto em uma rede responsiva de discursos, enunciação perene, paradoxal, urgente, necessária. Cumpre destacar que o objetivo almejado, qual seja: Construir, por meio de uma sequência didática, com estudantes do Ensino Médio integrado a Cursos Técnicos, artigos de opinião de modo que com a edição, reescrita, apropriação metalinguística e publicitação, pudessem ensejar a produção de vídeos compartilhados em diferentes redes sociais, foi alcançado e, para além disso, possibilitou a elaboração de percepções que foram sendo co-construídas processual e dialogicamente durante o trabalho desenvolvido. Assim, a produção narrativizada ratificada na virtualidade o que fora conceituado por Roldão há mais de duas décadas, quando o cenário pandêmico sequer poderia ser vicejado: 
A situação actual indicia assim a necessidade de reinvestir a débil profissionalidade docente no predomínio da função de ensinar-fazer aprender alguma coisa a alguém, sem o que a profissão docente se encontra condenada ou a um esvaziamento de sentido social, ou a uma ineficácia persistente geradora do seu descrédito [...] Ensinar não se tornou socialmente supérfluo, bem pelo contrário. A ampliação e diversificação dos sujeitos que frequentam as escolas, inseridas em sociedades que exigem qualificações crescentes extensivas à totalidade da teia social, cada vez mais conduz, na perspectiva que eu aqui defendo, a um reforço da premência social da função de ensinar. (ROLDÃO, 2004, p. 99).

Por fim, cumpre enfatizar que em tempos de exceção, tempos trágicos, mais se deve equalizar as relações humanas, e, sem lugar a assombros, não há lugar de humanização que possa prescindir de autêntica dialogia, inclusive quando os encontros se dão virtualmente, mais dialógicos devem ser, posto que o diálogo é o encontro entre mundos, dos quais nenhum dos participantes sai como entrou, pois se modificam mutuamente na ação de ouvir e ser ouvido por outrem e haver proposto a si mesmo novas perguntas no horizonte de perspectivas que se lhe apresenta. (GADAMER, 2002).

\section{REFERÊNCIAS}

ANDRADE, Oswald de. A descoberta, Erro de Português, Vício na fala, e pronominais. Comunicação \& Educação, n. 24, p. 98-99, 2002.

BAKHTHIN, Mikail. Estética da Criação Verbal. Translated Paulo Bezerra. 2003.

BERGMANN, Jonathan. Sala de aula invertida: uma metodologia ativa de aprendizagem; tradução Afonso Celso da Cunha Serra. 1. ed. Rio de Janeiro: LTC, 2018.

CLANDININ, D. Jean; CONNELLY, F. Michael. Pesquisa Narrativa: experiências e história na pesquisa qualitativa. Tradução: Grupo de Pesquisa Narrativa e Educação de Professores ILEEL/UFU. Uberlândia: EDUFU, 2011.

GADAMER, Hans-Georg. Verdade e método II: complementos e índices. Tradução de Ênio Paulo Giachini. Petrópolis, Rio de Janeiro: Vozes, 2002.

GOMES EVANGELISTA, Edson. Narrativas de professores de língua portuguesa e língua espanhola em processo inicial do tornar-se docente em contextos institucionais. Tese de Doutorado, UFMT, 2017.

MORAES, Vinícius de. Soneto da Separação. In: DE MORAES, Vinícius Livro de sonetos. São Paulo: Companhia das Letras, 2020.

MOREIRA, J. António; HENRIQUES, Susana; BARROS, Daniela Melaré Vieira. Transitando de um ensino remoto emergencial para uma educação digital em rede, em tempos de pandemia. Dialogia, p. 351-364, 2020.

RIBEIRO, Ana Elisa. Letramento digital e ensino remoto: reflexões sobre práticas. Debates em Educação, Maceió, Vol. 12. Número Especial 2, 2020. 
ROLDÃO, Maria do Céu. Função docente: natureza e construção do conhecimento profissional. Revista Brasileira de Educação v. 12 n. 34 jan./abr. 2007.

SCHNEUWLY, Bernard; DOLZ-MESTRE, Joaquim. Gêneros orais e escritos na escola. Mercado de Letras, 2004. 